\title{
Evidence calls for practice change in intramuscular injection techniques
}

\author{
Pamela K. Strohfus ${ }^{* 1}$, Oya Paugh ${ }^{2}$, Chelsea Tindell ${ }^{1}$, Paula Molina-Shaver ${ }^{1}$ \\ ${ }^{1}$ School of Nursing, Boise State University, Boise, Idaho, United States \\ ${ }^{2}$ Independent Researcher, San Diego, United States
}

Received: September 11, 2017

Accepted: October 13, 2017

Online Published: October 20, 2017

DOI: $10.5430 /$ jnep.v8n2p83

URL: https://doi.org/10.5430/jnep.v8n2p83

\begin{abstract}
Background and Objective: Intramuscular (IM) injections are administered to patients in all health care settings. Even though this procedure is invasive and the evidence supporting the process of administration is extensive, techniques and procedures vary throughout the literature and in practice. The purpose of this descriptive correlational study was to 1) investigate the literature on current evidence-based IM injection procedures pertaining to gender, patient weight, injection site, needle length, and technique, 2) compare surveyed healthcare personnel self-reported IM injection practices, and 3) query respondents on informational resources they access, continuing education they receive, and their years of healthcare experience and higher education.

Methods: The Intramuscular Injection Questionnaire (IIQ) was sent via email to various professional healthcare facilities and their respective social media sites. Two hundred and six (206) healthcare personnel of various healthcare backgrounds and educational levels accessed the IIQ via a link to Qualtrics software. SPSS Version 24 was used for data analysis.

Results: Most respondents were registered nurses with 4-15+ years of experience. Seventy-eight percent of respondents considered their IM injection knowledge at above average or expert levels. Gender was not considered an important factor when selecting an injection needle among $75 \%$ of participants. Of all respondents, $61 \%$ use z-track technique, $59 \%$ use the ventrogluteal site and 34\% always bunch or stretch the skin during injection. IM injection education was not provided in $75 \%$ of healthcare facilities.

Conclusions: IM injection practices vary among respondents and in the literature; some reported practices are contrary to current evidence-based practice. While the evidence provides some sound recommendations, some procedures are not well-documented or supported including in nursing texts. Nurses and other healthcare personnel must critically analyze the site, depth, needle, volume, medication, vaccine, and whether to bunch or stretch, according to evidence-based practice. Healthcare facilities should provide IM injection education routinely to ensure safe practices. Future studies (Level 1 and 2) are needed to further demonstrate the best evidence leading to safe and effective IM injections.
\end{abstract}

Key Words: Intramuscular injections, Nursing education, Patient safety, Injection practices, Evidence based practice

\section{INTRODUCTION}

A nurse at a primary care clinic received an order to administer penicillin $\mathrm{G}$ benzathine injections $(4 \mathrm{ml})$ intramuscular into deep muscle every 3 weeks to a male patient with a BMI of 55. Since this patient was in a wheelchair and immobile due to his obesity, she was limited to giving this injection

\footnotetext{
${ }^{*}$ Correspondence: Pamela K. Strohfus; Email: pamstrohfus@boisestate.edu; Address: School of Nursing, Boise State University, 1910 University Drive, Boise, Idaho, United States. 
into the vastus lateralis. She consulted the physician and Infectious Disease department to see if the patient could get this medication by another route or if an alternative treatment was available. With no alternative treatment available, the nurse requested ultrasound guidance to ensure delivery of the medication into muscle, but was ordered to go ahead and give the injection. Previously the patient received Bicillin injections with 1.5-inch needles without improvement in his condition. The nurse ascertained that injecting Bicillin with a 1.5-inch needle was not reaching the muscle and received permission to give the injection via a 3.5-inch spinal needle in the vastus lateralis. The patient's condition improved.

Are the medications we inject reaching the muscle? Intramuscular (IM) injections are administered to patients in all healthcare settings, and correct delivery of IM injections into the muscle is crucial for therapeutic efficacy of many drugs and vaccines. The purpose of this study is to review current evidence-based IM injection practice literature and compare with IM injection practices currently used by healthcare personnel. We also want to know what resources personnel access when they have questions about IM injections. Additionally, we will provide recommendations for evidencebased IM injection practices.

\section{Problem}

\subsection{Practice variation}

While appropriate IM injection technique is important for optimum action of drugs and vaccines, IM injections are performed in numerous ways by various healthcare personnel. In the scenario described above, some personnel would not have questioned the physician's order or if the needle reached the muscle, other personnel would base their IM practices on generational learning or formal schooling instruction.

Many medications like Bicillin are not as effective if delivered into subcutaneous tissue rather than muscle. Literature identifies medications such as risperidone, epinephrine, Depo-Provera, human chorionic gonadotropin (hCG), and Hepatitis A and B, rabies, and tetanus vaccines that if given into the subcutaneous tissue do not reach therapeutic effectiveness. ${ }^{[1-3]}$

Instructions for IM injection technique vary in literature and in nursing texts, including guidelines for weight and gender, injection site, needle gauge and length, bunching or stretching the skin, aspiration, and z-track method.$^{[4,5]}$ As an example, educational texts offer inconsistencies in IM injection practices pertaining to z-track technique. To reduce medication leakage out of the muscular tissue onto the skin post injection, z-track method (displacing the skin) has been recommended by many nursing texts and the litera- ture for decades. ${ }^{[6-9]}$ This procedure causes less discomfort and fewer IM adverse effects than the "traditional" injection method yet the variation of use in educational resources and in practice is notable. ${ }^{[10]}$

As obesity rates are rising, healthcare personnel must increasingly consider gender when giving IM injections. Overweight and obese women have more subcutaneous tissue over IM injection sites and require longer needles to reach muscle. Current evidence guides practice to consider gender when administering an IM injection. ${ }^{[2,3,11-13]}$

Recent evidence recommends ventrogluteal site be the preferred site for IM injections. ${ }^{[14,15]}$ Evidence shows the ventrogluteal site is far from major vascular and nerve structures and has a relatively low subcutaneous thickness in comparison with the traditionally used dorsogluteal site. ${ }^{[14,16,17]}$ Although studies recommend the ventrogluteal site, it is often not used by healthcare providers, especially in obese patients, due to its overall difficulty with patient positioning and landmarking. ${ }^{[14]}$

While bunching, and stretching of the skin is part of many respondents' practice, evidence does not support this practice for any patient other than those who are infants, geriatric, or emaciated. ${ }^{[18]}$ In addition to practice variation, evidence reveals other factors leading to ineffective IM injections including injection depth, especially in obese populations, limited IM injection education and varying information from reputable resources. ${ }^{[4,11,19]}$

\subsection{Injection depth}

Inadequate injection depth of IM injections due to needle length is not a new problem. ${ }^{[20,21]}$ Even with documented concern in the literature, populations such as asthma patients, women, and overweight and obese children and adults continue to be impacted by needles not reaching muscle. $^{[3,12,17,22-25]}$

Subcutaneous fat distribution differs by gender, age, and ethnicity and determines the thickness of subcutaneous tissue at the IM injection site. For a male with a BMI of 25, a 1-inch needle may be sufficient for an IM injection at the deltoid, but a female with a BMI of 25 and above will most likely require a 1.5 -inch-long needle to reach the deltoid muscle due to a thicker fat pad. ${ }^{[21]}$ As rates of obesity increase, longer needles are required to reach muscle, but they are not usually available to most healthcare staff in the United States. Becton, Dickinson, and Company (BD) manufactures a 21-gauge 2-inch needle, but since these are not safety needles, employers are reluctant to provide them due to potential needle stick injuries. ${ }^{[26]}$

While manufacturers' recommendations are prescriptive, 
they are not always complete. Manufacturers of vaccines and medications specify the route and injection site based on route and site used in clinical trials, but they rarely state patient weight or gender of the studied population and instrument data such as needle length. ${ }^{[27,28]}$ Another manufacturing problem is the "one size fits all" auto injectors used with medications such as epinephrine. The typical needles used in these injectors are often too short to reach muscle in heavier populations, including women and children. ${ }^{[11,29]}$ Manufacturers recommending or providing appropriately sized needles to reach the target tissue is important to ensure efficacy of the medications and vaccines.

Some vaccines do not reach full efficacy if given into the subcutaneous tissue rather than muscle. Tdap is one of the most common vaccines given IM to adults in most healthcare settings. Most patients receive this vaccine IM in the deltoid unless special circumstances exist. ${ }^{[30]}$

\subsection{IM Injection education}

There is wide variation in formal IM injection education among healthcare personnel. Registered nurses (RNs) and licensed practical nurses (LPNs) receive training on intramuscular injections and other skills, as well as biology, anatomy, pathophysiology, and pharmacological theory in formal programs and are licensed by their respective state board of nursing. Other healthcare workers such as medical assistants (MAs) receive limited vocational or no formal training in IM injections; some are taught by providers who may or may not be updated in current evidence-based techniques. ${ }^{[31-33]}$ Health care organizations may or may not provide continuing education for healthcare personnel after they have been hired, especially in injections.

\subsection{Resources}

IM injection recommendations from the Advisory Committee of Immunization Practices (ACIP) at the Centers of Disease Control and Prevention [CDC] and World Health Organization [WHO] are vague related to needle size, gender, weight/BMI of the patient, and injection site. ${ }^{[30,34]}$ These guidelines for large or obese patients currently recommend using 1-1.5-inch needles for patients $260+$ pounds. ${ }^{[4,5,30,34]}$ Even though worldwide injection practices are based on these guidelines, there is increasing evidence validating IM injections with a 1.5-inch long needle may not be reaching muscle, especially in females exceeding a BMI of 30..$^{[2,11,35]}$ Additionally, educational texts may vary in their instructional information related to injection practices.

Based on documented IM injection procedure concerns, this IM injection study explores the premise that healthcare personnel are using current evidence-based practice in their

Published by Sciedu Press healthcare settings and access appropriate resources for information.

\section{MeTHODS}

This is a descriptive correlational study to elicit information via a survey of healthcare personnel who administer intramuscular injections. Descriptive and analytical statistics were used to describe the demographic characteristics of the sample and study variables.

\subsection{Setting}

The Intramuscular Injection Questionnaire (IIQ) was sent to various professional organizations including hospitals, urgent and primary care settings. The survey was then distributed via email to healthcare personnel administering IM injections. The survey link was also posted on two professional healthcare social media sites. On these platforms the Qualtrics survey was accessible via a link limiting only one survey attempt per computer.

\subsection{Participants}

The study population included personnel of various healthcare backgrounds and educational levels. Healthcare personnel were asked to participate from various organizations. Participants were 18 through over 60 years of age.

\subsection{Design}

The IIQ was modified from a previous survey by adding 21 more questions, 11 of which were specifically addressing IM sites, and needle choices/availability; and 9 questions specific to respondent demographics. ${ }^{[6,36]}$ Three academic faculty with questionnaire experience reviewed the added questions to ensure content validity; the IIQ specifically addressed intramuscular injection practices, frequency of injection, injection education and training, needle and site choices, and situational questions.

\subsection{Measures}

Two hundred and six (206) participants completed the IIQ. Surveys with less than nine responses were excluded. The demographic questions elicited information on age, gender, job type, facility type, educational levels, and years of experience for those who administer intramuscular injections.

Data from completed surveys were analyzed using SPSS, version 24. Frequencies and descriptive statistics were used from 5-7 point Likert scale responses. The Chi-square test was used to evaluate differences among groups. The IIQ injection study was approved by the Institutional Review Board of the university. 


\section{Results}

As shown in Table 1, of 206 participants the largest respondent job type were RNs, LPNs, and MAs; all were between the ages of 19-60+ years, and two-thirds had seven to $15+$ years of healthcare experience.

Table 1. Demographic of respondents

\begin{tabular}{|c|c|c|c|}
\hline Category & & $\mathbf{N}$ & $\%$ \\
\hline \multirow{9}{*}{ Job Type } & MA & 19 & 9.2 \\
\hline & LPN/LVN & 26 & 12.6 \\
\hline & $\mathrm{RN}$ & 142 & 68.9 \\
\hline & NP & 2 & 1 \\
\hline & $\mathrm{MD}$ & 5 & 2.4 \\
\hline & PA & 2 & 1 \\
\hline & Pharmacist & 2 & 1 \\
\hline & EMT & 1 & 0.5 \\
\hline & Other & 7 & 3.4 \\
\hline Total & & 206 & 100.0 \\
\hline \multirow{6}{*}{ Age } & Under 20 & 1 & 0.5 \\
\hline & $20-29$ & 39 & 18.9 \\
\hline & $30-39$ & 54 & 26.2 \\
\hline & $40-49$ & 43 & 20.9 \\
\hline & $50-59$ & 54 & 26.2 \\
\hline & Over 60 & 15 & 7.3 \\
\hline Total & & 206 & 100.0 \\
\hline \multirow{11}{*}{$\begin{array}{l}\text { Practice } \\
\text { Setting }\end{array}$} & 0 & 2 & 1 \\
\hline & Family Practice & 15 & 7.3 \\
\hline & Pediatrics & 38 & 18.0 \\
\hline & IM Outpatient & 14 & 6.8 \\
\hline & Acute Care & 69 & 33.5 \\
\hline & Community Health & 11 & 5.3 \\
\hline & Long Term Care & 3 & 1.5 \\
\hline & ER/Urgent Care & 21 & 10.2 \\
\hline & Primary Care & 23 & 11.2 \\
\hline & Behavioral Health & 9 & 4.3 \\
\hline & Pharmacy & 2 & 1.0 \\
\hline \multirow[t]{3}{*}{ Total } & & 206 & 100.0 \\
\hline & 0 & 1 & 0.5 \\
\hline & $0-3$ & 33 & 16.0 \\
\hline Years' & $4-6$ & 32 & 15.5 \\
\hline \multirow[t]{4}{*}{ Experience } & $7-10$ & 29 & 14.1 \\
\hline & $11-14$ & 26 & 12.6 \\
\hline & 15 and over & 85 & 41.3 \\
\hline & & 206 & 100.0 \\
\hline
\end{tabular}

\subsection{Practice variation}

When considering gender of the patient, of 206 participants only $27(13 \%)$ always consider gender, 31 (15\%) often and $50(21 \%)$ sometimes consider gender, and $97(47 \%)$ rarely or never consider gender. Of the job types RN, LPN, and MA, $51(\mathrm{n}=52 ; 28 \%)$ stated they always or often consider gender when giving IM injection and 134 (72\%) stated they sometimes or never consider gender when giving IM injection.

When asked how confident respondents are in administering an IM injection in the ventrogluteal site, $116(59 \%)$ felt confident (RNs $\mathrm{n}=87 ; 61 \%)$ injecting into this site $\left(\chi^{2}=158\right.$; df $=48 ; p<.000)$. The other $90(41 \%)$ respondents did not use, know, or been trained to use the ventrogluteal site. Overall variability in knowing or not knowing how to administer a ventrogluteal IM injection was significant $\left(\chi^{2}=77.221\right.$; $\mathrm{df}=$ $35 ; p<.000)$. Respondents were not overly confident to use the ventrogluteal as a preferred site.

Results revealed 62 (34\%) respondents always or often bunch or stretch the skin before the needle is injected into the skin; $89(48 \%)$ stated it depended on the patient; and 34 (18\%) did not bunch or stretch at any time. The most common reason for bunching or stretching was they have always done it this way.

MAs, LPNs, and RNs 114 (61\%) use z-track technique some, most or all of the time when administering an IM; 55 (30\%) did not use or know what the z-track technique was; and another 18 (9\%) chose not to answer. Ninety-two (65\%) RNs use z-track some, most, or all of the time. Overall variability in knowing or not knowing about or using z-track was significant ( $\left.\chi^{2}=73.88 ; \mathrm{df}=42 ; p=.002\right)$. The preference to use z-track was not equally distributed among the respondents.

Respondents were asked if they considered themselves as expert/above average or had some/little knowledge in IM injection practices. For those who self-reported they possessed expert or above average knowledge were inconsistent in evidence-based practices of bunch/stretch, gender, height/weight or injection site consideration. While 164 $(88 \%)$ of the self-claimed above average to expert knowledge consider the site of injection; only 51 (21\%) consider the gender always or most of the time (see Table 2).

When considering years of experience with evidence-based practices of bunch/stretch, gender, and injection site consideration, the majority of respondents considered injection sites when giving an injection regardless of healthcare experience. Forty eight percent of the respondents rarely or never considered gender $(n=185)$; of which $40 \%(n=34)$ were in healthcare 15 years or more. Bunching or stretching the skin before the injection was practiced regardless of experience (see Figure 1).

\subsection{Injection depth}

When asked what needle length they used the most, respondents selected 1 -inch the most $(n=77)$ followed by 1.5 -inch $(n=67)$. Of those who considered themselves an expert or have above average knowledge, 68 use 1-inch the most followed by 60 using 1.5-inch the most. Of those who administer frequently (weekly or more), 48 (53\%) respondents use 1 -inch the most and $38(42 \%)$ respondents use 1.5-inch 
needle the most. RNs use 1-inch and 1.5-inch equally; LPNs 2-inch needles.

and MAs use 1-inch the most. Only 9 respondents have used

Table 2. Self-reported expert or above average knowledge respondents use or consider when administering an IM injection

\begin{tabular}{llllll}
\hline & All of the time & Most of the time & Some of the time & Rarely & Never \\
\hline Bunch & 24 & 25 & 36 & 38 & 19 \\
Stretch & 19 & 18 & 36 & 27 & 52 \\
Gender & 23 & 28 & 17 & 5 & 46 \\
Weight/Height & 106 & 31 & 14 & 2 & 2 \\
Injection site & 99 & 33 &
\end{tabular}

Three IM injection case scenario questions were asked relating to giving IM injections of Tdap (tetanus, diphtheria, acellular pertussis), flu vaccine, and Depo-Provera. In the survey, we asked which site and route to give a Tdap injection to a 65-year-old man, 37 (18\%) chose to give Tdap subcutaneous, ventrogluteal, dorsogluteal, or didn't know. Alternately, 163 respondents were $80 \%$ correct when giving the flu vaccine to a 450-pound patient into the deltoid with a 1.5 -inch or greater needle. ${ }^{[37]}$

Depo-Provera is a common IM injectable medication for contraception given to women in outpatient clinic settings. The manufacturer specifies that Depo-Provera is to be administered by deep IM injection in the gluteal or deltoid muscle. ${ }^{[38]}$ This medication is often supplied as a prefilled syringe with 1.5-inch needle. In the survey, we asked participants where they would inject this medication into a 350-lb. woman and with what size needle. Of the respondents, 32 would administer Depo-Provera into the ventrogluteal or dorsogluteal site with a 1.5 -inch needle, 46 would give the injection into the ventrogluteal or dorsogluteal site with a 2-inch needle, and 29 would give the injection into the deltoid site with a 1.5 -inch needle. Four chose to give the injection into the deltoid site with a 2-inch needle. Thirty-six (33\%) gave the injection incorrectly and 78 (66\%) gave it correctly by choosing ventrogluteal or dorsogluteal site with a 2-inch needle or into the deltoid site with a 1.5 -inch needle.

\subsection{IM Injection education}

Of the respondents, $155(75 \%)$ state they receive no additional training or education in their practice settings beyond their initial formal education.

\subsection{Resources}

A review of nursing skills textbooks was conducted to elicit IM injection techniques. Nursing skill textbooks from three schools of nursing were assembled. The list was refined by date (less than 5 years old), resulting in 15 texts. Five of the most utilized texts among the schools of nursing were

Published by Sciedu Press selected with two different publishers. ${ }^{[7,9,39-41]}$ Noted differences in the texts related to site, needle length, bunch or stretching the skin, and z-track use. Current level one and two evidence (RCT, quasi-experimental with or without metaanalysis) was lacking in all textbooks, many often citing other textbooks as evidence. ${ }^{[42]}$ No scientific evidence supported any IM practice procedure in any of the five texts. ${ }^{[7,9,39-41]}$

Of 206 respondents, $69(40 \%)$ stated they usually accessed information on IM injections from co-workers (33\%) whereas $19(9 \%)$ read printed information. The internet was preferred by $32(16 \%)$ and $24(12 \%)$ found information some other way. Of the 19 MA respondents, 11 (58\%) asked coworkers for information whereas $66 \mathrm{RNs}$ choose to read or look up information $(46 \%)$ on the internet rather than ask a coworker $(28 \%)$.

\section{Discussion}

Based on our study, current evidence-based IM injection techniques are not consistently recommended or applied which may alter the effectiveness of IM injections.

\subsection{Practice variation}

As evidenced by IIQ results, nurses and healthcare personnel vary widely in considering gender, weight/height and/or body mass index (BMI), needle sizes, and IM injection sites. Approximately half of respondents $(n=97)$ rarely or do not consider gender at all even though two-thirds consider injection site and height/weight when preparing to administer an IM. The results add to the evidence that most healthcare personnel choose injection sites and needles without regard to gender.

The results affirmed the z-track procedure is widely variable among healthcare personnel. One third of the respondents did not know how to use the z-track technique or the purpose of it. Even though the literature has supported the z-track for years (not vaccines), current evidence may not be fully used in practice. ${ }^{[6,8]}$ 
Evidence supports the use of the ventrogluteal site for deep IM injections. ${ }^{[14,15]}$ Fifty-five $(41 \%)$ of the 206 respondents did not know of, ever use, or know how to locate this site. Even though the literature supports using ventrogluteal site, it is not being fully used in practice.

Our results show one-third of respondents always bunch or stretch the skin during an injection based on the way they have been taught or because 'they have always done it this way'. While bunching, and stretching of the skin is part of many respondents practice, evidence does not support this practice for any patient other than those who are infants, geriatric, or emaciated. ${ }^{[18]}$

When considering years of experience, we surmised that respondents would demonstrate less evidence-based practice the more experienced they were. The majority of respondents considered injection sites when giving an injection regardless of healthcare experience. Bunching or stretching the skin before the injection was practiced regardless of experience. Respondents 'rarely or never considered gender' increased in the more practiced personnel which may reflect on obesity rates not being a consideration when they first started their practice.

We can surmise efficacy of medications/vaccines may be affected if current evidence-based processes are not integrated into practice with regards to gender, BMI, needle sizes, and sites when preparing for an IM injection. ${ }^{[2,11,13,43]}$ Continuous education based on current evidence is vital to providing safe quality care.

\subsection{Injection depth}

Even though evidence validates the use of longer needles based on weight or BMI, our study shows that few healthcare personnel use appropriately sized needles, specifically 25-gauge and 1-inch needles the most. ${ }^{[2,11,44-46]}$ Critical assessments of patient weight, BMI, gender and injection site, needle length, volume of medication before administering IM injections is important and therefore should drive practice change.

If the CDC recommends a longer needle size based on weight greater than $260 \mathrm{lbs}$. or BMI 35 and manufacturing companies produce longer needles with safety locks, practice change could occur. Recent studies show the need for longer needles but our survey shows longer needles are seldom available in the United States. ${ }^{[12,20,25]}$

Autoinjectors supplied with standard-sized needles are too short for obese patients and overweight women, which can lead to unfortunate consequences, especially with epinephrine autoinjectors. ${ }^{[11,19]}$ Again, practice change would occur if manufacturers utilize current evidence to produce autoinjectors with varied sized needles based on weight or BMI. Similar to changing practice from heparin flushes to normal saline flushes in order to maintain patency of intravenous lines demonstrates evidence and practice, together can produce viable solutions to improve practice and quality of care. ${ }^{[47,48]}$

Most respondents had varied answers to several case scenario questions. Tdap is one of the most common vaccines given IM to adults in healthcare settings and is specifically given IM into the deltoid muscle. ${ }^{[37]}$ Site choices for Tdap demonstrated variability among all job types reflecting inadequate knowledge among personnel.

Depo-Provera is a common IM injectable medication for contraception given in the outpatient clinic settings. The manufacturer specifies that Depo-Provera is to be administered by deep IM injection in the gluteal or deltoid muscle. When giving Depo-Provera to an obese woman, $33 \%$ chose incorrect answers. The correct evidence-based procedure is to inject Depo-Provera into the gluteal muscle with an appropriately sized needle based on weight or BMI, or into the deltoid with a 1.5-inch needle if the woman is over 200 pounds. ${ }^{[38]}$ RNs chose appropriate needle sizes more often (1-inch and 1.5-inch needles equally) based on patient weights than less educated healthcare personnel indicating evidence of higher level of education. The level of education may be an important consideration in both inpatient and outpatient settings. ${ }^{[31]}$

Even though respondents were $80 \%$ correct when giving the flu vaccine to a 450-pound patient into the deltoid with a 1.5-inch or greater needle, consider mass flu clinics using 1-inch needles as the default needle for influenza vaccine injections; these needles may not be adequate for IM injections in obese populations. For a male with BMI 25-30, a 1-inch needle may be sufficient for an IM injection at the deltoid but a female with BMI of 30 and above most likely will require a 1.5-inch long needle at the deltoid due to a thicker fat pad. ${ }^{[21]}$ Are healthcare personnel considering using longer needles for patients with BMIs over 30 at flu clinics, especially in women? If the flu vaccine is not administered into muscle, the efficacy may be reduced. ${ }^{[3,27]}$

\subsection{IM Injection education}

Most respondents had 4 through $15+$ years' experience in healthcare, indicating the majority was experienced. If coworkers have been in healthcare for several years like 132 (64\%) of our respondents, the information they provide may not be evidence-based. Furthermore, three fourths of those surveyed receive no additional training or education in their practice settings yet evidence-based practice continues to 
change at a rapid rate. Additional training might help update and improve IM injection practice. ${ }^{[49,50]}$

Healthcare organizations must provide education to healthcare personnel to prevent competency drift. Moving toward implementing evidence-based practice in our workplaces will require frequent continuing education, revision of standards and guidelines, and policies/procedures made available to healthcare personnel. Nurses and providers need to keep current on evidence-based changes in injection techniques and offer appropriate education to other healthcare workers including MAs. ${ }^{[4,49]}$ If properly trained in IM injections, the percentage of successful IM injections could increase from $52 \%$ to $72 \%$. ${ }^{[20]}$

Review of nursing textbooks reveals variations in intramuscular (IM) injection site recommendations and techniques. ${ }^{[4,5]}$ While the information was similar from text to text, no standard recommendations could be drawn related to needle size based on weight, bunching, or stretching, and site selection.

Additionally, textbooks cite little to no high-level research supporting IM injection procedures, i.e., RCTs, systematic reviews, or quasi-experimental studies to support practice. ${ }^{[39,40,42]}$ All medical and nursing texts must provide current high-level evidence when guiding practice. If current evidence is not transferred to practice, efficacy of the medication may be compromised.

\subsection{Resources}

MAs mainly ask co-workers for information rather than going to a resource such as the manufacturers insert information or CDC website ${ }^{[51]}$ In comparison RNs have a tendency to look up information more frequently than the other personnel studied.

Educational texts do vary in their instructional information related to injection practices. ${ }^{[7,9,39-41]}$ Publishers and authors of educational texts must consider the most current level one and two evidence when writing procedures and techniques for IM injections.

\section{RECOMMENDATIONS}

\subsection{Future study}

Further research is recommended based on our survey results, most importantly studies are needed to estimate needle sizes and techniques to use with variously weighted patients using ultrasound and serum titers. Additionally, we recommend adopting BMI as a standard to determine appropriate needle length throughout the United States comparable to other countries conducting similar research. ${ }^{[6,11,12,24,25]} \mathrm{We}$ recommend the CDC and WHO update IM injection recommendations to include BMI and needle length based on various sized populations. ${ }^{[33,52]}$ Lastly, additional research on thickness of subcutaneous tissue (fat pad) is needed similar to Poland's study in 1997. ${ }^{[53]}$

\subsection{Continuous education}

Training in proper IM injection technique needs additional review. Differences in training between RNs, LVNs, MAs, and medical assistants may account for the wide range of technique demonstrated in the study. Evidenced-based practice of IM injection technique may require additional research to standardize training methods and teaching materials such as textbooks. As injection practices change based on evidence, IM injection education is an important consideration both in formal institutions and in healthcare organizations for retraining.

\subsection{Reporting of methodological data}

Drug manufacturers may not be providing adequate clinical guidance for IM injectable products based on important methodological data such as individual weight, needle size, injection site, and individual therapeutic response. ${ }^{[15]}$ As an example, if average weights of drug trial subjects are less than 200 pounds and include only Caucasian men $20-40$ years of age, this information should be readily transparent to the consumer. Manufacturers must consider the growing obesity problem worldwide and expand their trials to include various weighted populations. As important, when drug manufacturers package needles with IM injectable medication, they must guide practice by providing appropriately sized needles according to various BMIs or weights of patients. ${ }^{[19,43]}$

\section{Limitations}

There were several limitations to this study. Ideally more respondents would add more credence to these results. Conducting a social media survey depends on respondents accessing and completing the survey. Even though there was an adequate response for the purposes of this study, more participants may have provided different results. These respondents were mainly from the western United States; it could be that healthcare personnel from other regions or countries may have produced varying results. Most of the respondents were RNs, LPNs, and MAs; it could be that participant pools from other healthcare facilities, like pharmacies, may have shown different results.

\section{Implications for nursing practice}

Nurses and other healthcare personnel must use clinical judgement when giving IM injections. Various sized patients will require various sized needles. The nurse must determine if the injectable vaccine or medication is going to reach muscle in her/his patient. This requires considera- 
tion of injectable medication type and volume, injection site, gender, and weight/BMI and injection technique. Nurses should not bunch or stretch the skin before IM injection for any patient other than those who are pediatric, geriatric, or emaciated. ${ }^{[18]}$ Longer needles with safety locks should be available in all healthcare facilities and nurses/other personnel must be trained to use longer needles. ${ }^{[12,20,25]}$ Patients weighing greater than 260-pounds or 30+ BMI may require a muscle depth assessment prior to IM injection.

We recommend the availability of various length needles at flu vaccine clinics to ensure flu vaccine delivery into muscle for individuals with BMIs over 30, especially women. ${ }^{[3,21,27]}$

Healthcare facilities should provide a variety of needles with different lengths and gauges, including $2+$ inch safety needles. ${ }^{[25]}$ In addition, requiring a clinical assessment of morbidly obese patients by a clinical nurse specialist, nurse practitioner or other specialized nurse before IM injections are given should be a standard within all healthcare facilities. This may require an assessment of patient mobility status and ultrasound guidance to determine the appropriate needle length at the injection site. If healthcare personnel determine that injection into muscle is questionable at the required injection site due to unavailability of appropriately long needle, they should refrain from giving the injection and defer to prescribing MD for further instructions.

Finally, larger institutions should consider having site "champions" who can be consulted for questions related to injections. These specially trained champions would be licensed healthcare personnel who stay current on evidence-based IM injection procedures. Since most healthcare personnel prefer receiving information and guidance from their peers, this would likely be effective and well received.

\section{Conclusion}

Though some IM injection procedures have changed over the last two decades, this study shows IM injection practices vary among healthcare personnel in 2016. Best practices must include appropriate sites for injection, standardized injection techniques, and individualized needle length based on patient weights and gender. ${ }^{[20]}$ Furthermore, manufacturer recommendations and procedures in educational texts must be based on sound evidence as these guide practice. Conducting studies (Levels one and two) validating the effect of IM injections not reaching the muscle in various weighted patients would add credence to revising recommendations from the CDC and WHO.

In summary, while evidence supporting the process of administration is extensive, techniques and procedures vary throughout the literature and in practice, potentially hindering IM injections efficacy. To assure medication efficacy, current evidence-based practice from the literature supports critical assessments of patient weight, BMI, gender and injection site, needle length, volume of medication before administering IM injections.

\section{CONFlicts of InTERest Disclosure}

The authors declare that there is no conflict of interest.

\section{REFERENCES}

[1] Palma S, Strohfus P. Are IM injections IM in obese and overweight females? A study in injection technique. Appl Nurs Res [Internet] 2013; 26(4): e1-4. https://doi.org/10.1016/j.apnr. 2013. 09.002

[2] Shah DK, Missmer SA, Correia KFB, et al. Pharmacokinetics of human chorionic gonadotropin injection in obese and normal-weight women. J Clin Endocrinol Metab [Internet]. 2014 Apr [cited 2016 Sep 10]; 99(4): 1314-21. Available from: http://www.ncbi.nlm .nih.gov/pubmed/24476082

[3] Painter SD, Ovsyannikova IG, Poland GA. The weight of obesity on the human immune response to vaccination. Vaccine. $2015 ; 33$ 4422-9. http://doi.org/10.1016/j.vaccine.2015.06.101

[4] Davidson KM, Rourke L. Teaching best-evidence: Deltoid intramuscular injection technique. J Nurs Educ Pract [Internet]. 2013; 3(7): 120-8. http://doi .org/10.5430/jnep.v3n7p120

[5] Carter-Templeton H, McCoy T. Are we on the same page?: a comparison of intramuscular injection explanations in nursing fundamental texts. Medsurg Nurs. 2008; 17(4): 237-40. PMid:18807857

[6] Wynaden D. Administering intramuscular injections: How does research translate into practice over time in the mental health set- ting? Nurse Educ Today. 2015; 35(4): 620-4. PMid:25596035 https://doi.org/10.1016/j.nedt.2014.12.008

[7] Berman A, Snyder S. Skills in clinical nursing. 8th ed. Upper Saddle River, NJ: Pearson Prentice Hall.

[8] Yilmaz D, Khorshid L, Dedeoglu Y. The effect of the z-track technique on pain and drug leakage in intramuscular injections. Clin Nurse Spec. 2016; 30(6): 7-12. Available from: http://doi.org/ $10.1097 /$ NUR . 0000000000000245

[9] Smith SF, Duell D, Martin BC, et al. Clinical nursing skills: Basic to advanced skills. 9th ed. Upper Saddle River, NJ: Pearson Prentice Hall; 2016.

[10] Keen MF. Comparison of intramuscular injection techniques to reduce site discomfort and lesions. Nurs Res. 1986; 35(4): 207-10. http://doi.org/10.1097/00006199-198607000-00005

[11] Bhalla MC, Gable BD, Frey JA, et al. Predictors of epinephrine autoinjector needle length inadequacy. Am J Emerg Med [Internet]. 2013; 31(12): 1671-6. http://doi.org/10.1016/j.ajem. 201 4.01 .025

[12] Zaybak A, Ismailo lu EG, Ismailo lu E. Examination of subcutaneous tissue thickness in the thigh site for intramuscular injection in obese individuals. J Ultrasound Med [Internet]. 2015 Sep 1 [cited 2016 Jun 
13]; 34(9): 1657-62. http://doi.org/10.4236/health. 2013. 512262

[13] Middleman AB, Anding R, Tung C. Effect of needle length when immunizing obese adolescents with hepatitis $\mathrm{B}$ vaccine. Pediatrics [Internet]. 2010; 125(3): e508-12. http://doi .org/10.1542/pe ds. 2009-1592

[14] Coskun H, Kilic C, Senture C. The evaluation of dorsogluteal and ventrogluteal injection sites: A cadaver study. J Clin Nurs. 2016; 25(7-8): 1112-9. PMid:26868292 https://doi.org/10.1111/ jocn. 13171

[15] Yapucu Güneş Ü, Ceylan B, Bayindir P. Is the ventrogluteal site suitable for intramuscular injections in children under the age of three? J Adv Nurs. 2016; 72(1): 127-34. PMid:26420460 https : //doi.org/10.1111/jan.12813

[16] Mishra P, Stringer MD. Sciatic nerve injury from intramuscular injection: A persistent and global problem. Int J Clin Pract. 2010; 64(11): 1573-9. PMid:20670272 https://doi .org/10.1111/j.1742-1 $241.2009 .02177 . \mathrm{x}$

[17] Chan VO, Colville J, Persaud T, et al. Eur J Radiol. 2006; 58(3): 480-4. http://doi.org/10.1016/j.ejrad.2006.01.008

[18] Kroger A, Sumaya C, Pickering L, et al. Epidemiology and prevention of vaccine-preventable diseases. 13th ed. Centers of Disease Control and Prevention; 2015. 79-104 p.

[19] Arslan F, Uzun S, Fidanci BE, et al. Subcutaneous tissue of obese children may be too thick for injection solutions to reach intramuscular tissue. HealthMED. 2012; 6(1): 242-8.

[20] Boyd AE, Deford LL, Mares JE, et al. Improving the success rate of gluteal intramuscular injections. Pancreas [Internet]. 2013; 42(5): 878-82. http://doi.org/10.1097/MPA.0b013e318279d552

[21] Poland G. Determination of deltoid fat pad thickness. JAMA. 1997; 277(21): 1709-11. PMid:9169899 https://doi.org/10.1001/ jama.1997.03540450065037

[22] Davenport JM. A systematic review to ascertain whether the standard needle is more effective than a longer or wider needle in reducing the incidence of local reaction in children receiving primary immunization. J Adv Nurs. 2004; 46(1): 66-77. http://doi .org/10.1111/ j.1365-2648.2003.02966.x

[23] Diggle L, Deeks J. Effect of needle length on incidence of local reactions to routine immunisation in infants aged 4 months: randomised controlled trial. BMJ [Internet]. 2000; 321(7266): 931-3. http://doi.org/10.1136/bmj .38906.704549.7c

[24] Marshall HS, Clarke MF, Evans S, et al. Randomized trial using ultrasound to assess intramuscular vaccination at a 60 degrees or 90 degrees needle angle. Vaccine. 2013; 31(23): 2647-52. http: //doi.org/10.1016/j.vaccine. 2013.03.037

[25] Tanioka T, Sakamaki S, Yasuhara Y, et al. Optimal needle insertion length for intramuscular injection of risperidone long-acting injectable (RLAI). Health (Irvine Calif) [Internet]. 2013; 5(12): 193945. http://doi.org/10.4236/health.2013.512262

[26] Needlestick Prevention and Safety Act. 106th Congress; 2000.

[27] Herzog C. Influence of parenteral administration routes and additional factors on vaccine safety and immunogenicity: a review of recent literature. Expert Rev Vaccines [Internet]. 2014; 13(3): 399415. Available from: http://doi.org/10.1586/14760584.201 4.883285

[28] Poirier MK, Poland GA, Jacobson R. Parameters potentially affecting interpretation of immunogenicity and efficacy data in vaccine trials; are they adequately reported? Vaccine. 1996; 14(1): 25-7. https://doi .org/10.1016/0264-410X (95)00170-6

[29] Stecher D, Bulloch B, Sales J, et al. Epinephrine auto-injectors: is needle length adequate for delivery of epinephrine intramuscu- larly? Pediatrics. 2009; 124(1): 65-70. PMid:19564284 https: //doi.org/10.1542/peds.2008-3388

[30] Administering Vaccines: Dose, Route, Site, and Needle Size [Internet]. 2016. Available from: http://www.immunize.org/catg. d/p3085.pdf

[31] Strohfus PK, Kim SC, Palma S, et al. Immunizations challenge healthcare personnel and affects immunization rates. Appl Nurs Res. 2017; 33: 131-7. http://doi:10.1016/j.apnr.2016.11.005

[32] Taché S, Hill-Sakurai L. Medical assistants: the invisible "glue" of primary health care practices in the United States? J Health Organ Manag [Internet]. 2010; 24(3): 288-305. Available from: http://www.emeraldinsight.com/doi/10.1108 /14777261011054626 PMid:20698404 https://doi.org/10.1 $108 / 14777261011054626$

[33] Occupational Outlook Handbook [Internet]. U.S. Bureau of Labor Statistics. U.S. Bureau of Labor Statistics; 2015 [cited 2017Jul30] Available from: https://www.bls.gov/ooh/healthcare/med ical-assistants.htm\#tab-2

[34] Organization WHO. Immunization in Practice: A practical Guide for Health Staff.

[35] Zaybak A, Güneş ÜY, Tamsel S, et al. Does obesity prevent the needle from reaching muscle in intramuscular injections? J Adv Nurs. 2007; 58(6): 552-6. http://doi.org/10.1111/j.1365-2 $648.2007 .04264 . x$

[36] Wynaden D, Landsborough I, McGowan S, et al. Best practice guidelines for the administration of intramuscular injections in the mental health setting. Int J Ment Health Nurs. 2006; 15(3): 195-200. http://doi.org/10.1111/j.1447-0349.2006.00423.x

[37] Immunization Action Coalition. Available from: http://www.im munize.org/catg.d/p2020a.pdf

[38] Phizer Pharmaceuticals. DEPO-PROVERA- medroxyprogesterone acetate injection, suspension Pharmacia and Upjohn Company LLC. Available from: http://labeling.pfizer.com/ShowLabeling . aspx?id=522\#section-2

[39] Burton M, Ludwig JM. Fundamentals of nursing care: Concepts, connections \& skills. 2nd ed. Philadelphia, P.A.: F.A. Davis Company; 2015.

[40] Smith BT. Pharmocology for nurses. Burlington, MA: Jones Bartlett Learning; 2016.

[41] Taylor C, Lillis C, Lynn P. Fundamentals of Nursing (8th ed.) Philadelphia, P.A: Lippincott Williams \& Wilkins; 2014.

[42] Dearholt SL, Dang D. Johns Hopkins Nursing Evidence-Based Practice: models and guidelines [Internet]. 2nd ed. Indianapolis, IN: Sigma Theta Tau International; 2012. Available from: http://ww w.hopkinsmedicine.org/evidence-based-practice/_doc s/appendix_e_research_evidence_appraisal_tool.pdf PMid:22970528

[43] Stecher D, Bulloch B, Sales J, et al. Epinephrine auto- injectors: Is needle length adequate for delivery of epinephrine intramuscularly? Pediatrics. 2009; 124(1): 65-70. PMid:19564284 https: //doi.org/10.1542/peds.2008-3388

[44] Sakamaki S, Yasuhara Y, Motoki K, et al. The relationship between body mass index, thickness of subcutaneous fat, and the gluteus muscle as the intramuscular injection site. Health (Irvine Calif) [Internet]. 2013; 5(9): 1443-8. http://doi.org/10.4236/health .2013 .59196

[45] Cook IF. Best vaccination practice and medically attended injection site events following deltoid intramuscular injection. Hum Vaccines Immunother. 2015; 11(5): 1184-91. http://doi.org/10.1080/ 21645515.2015.1017694

[46] Dayananda L, Belaval VV, Raina A, et al. Intended intramuscular gluteal injections: are they truly intramuscular? J Postgrad Med 
[Internet]. 2014; 60(2): 175-8. http://doi.org/10.4103/0022 $-3859.132334$

[47] Alexander H. Heparin versus normal saline as a flush solution. Int J Adv Sci Arts. 2010; 1(1): 63-75.

[48] Mitsiou-Tzortzi M, Koutelekos I. Finding the evidence for keeping the patency in peripheral intermittent intravenous devices. Heal Sci J. 2008; 2(3): 121-8.

[49] Chiodini J. Best practice in vaccine administration. Nurs Stand [Internet]. 2001; 16(7): 35-8. http://doi .org/10.7748/ns2001.1 $0.16 .7 .35 . c 3109$

[50] Nicoll LH, Hesby A. Intramuscular injection: An integrative research review and guideline for evidence-based practice. Appl Nurs Res.
2002; 16(2): 149-62. https://doi.org/10.1053/apnr.2002. 34142

[51] Pravikoff DS, Tanner AB, Pierce ST. Readiness of U.S. nurses for evidence-based practice. Am J Nurs [Internet]. 2005; 105(9): 40-51. PMid:16138038 https://doi.org/10.1097/00000446-20050 9000-00025

[52] Recommendations of the Advisory Committee on Immunization Practices (ACIP). [Internet]. 2011. Available from: https://www . cdc.gov/mmwr/pdf/rr/rr6002.pdf

[53] Poland G, Borrud A, Jacobson R, et al. Determination of deltoid fat pad thickness. Implications for needle length in adult immunization. JAMA [Internet]. 1997; 277(21): 1709-11. Available from: http: //www.ncbi.nlm.nih.gov/pubmed/9169899 PMid:9169899 ht tps://doi.org/10.1001/jama.1997.03540450065037 